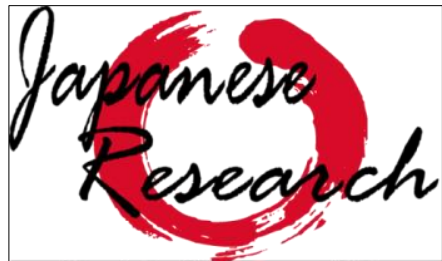

on Linguistics, Literature and Culture
Japanese Research on Linguistics, Literature, and Culture

Vol. 2 No. 2 May 2020, Hal. 178-198 ISSN online: 2655-4836

Doi: $10.33633 /$ jr.v2i2.3973

http://publikasi.dinus.ac.id/index.php/jrllc/article/view/3973/2029

japanese.research@fib.dinus.ac.id

Published by Universitas Dian Nuswantoro, Semarang

\title{
Tindak Tutur Penolakan Bahasa Jepang Oleh Mantan Kenshuusei (Pekerja Magang Di Jepang)
}

\author{
Dewi Novitasari, Bayu Aryanto \\ Universitas Dian Nuswantoro \\ Universitas Dian Nuswantoro \\ 312201600651@mhs.dinus.ac.id
}

Article History: Submitted date 2020-08-20; Accepted date 2020-09-01; Published date 2020-09-03

\begin{abstract}
This study is intended to describe the speech act strategy of rejection in Japanese language by former apprentices (kenshuusei). The descriptive qualitative method used in this research is under the approach of interlanguage pragmatic study because the participants are foreign speakers of Japanese. The data were collected using the oral-discourse completion test technique. The findings of this study have shown three types of refusal processes, namely 1) pre-refusal - main refusal - post refusal; 2) pre-refusal - the main refusal; and 3) major refusal - post refusal. In the refusal utterances, there are 2 forms of refusal, namely direct refusal and indirect refusal. The strategies used in refusing are apology strategy, refusal reason strategy, alternative statement strategy, hope statement strategy, future demand strategy, negation form, fukushi, and aizuchi. The refusal strategies mostly used by former apprentices are the excuse strategy for refusal and almost all refusal speeches also use apologies.
\end{abstract}

Keywords: speech acts, refusal utterance, refusal strategies, interlanguage pragmatics

\begin{abstract}
Abstrak
Penelitian ini bertujuan untuk mendeskripsikan strategi tindak tutur penolakan bahasa Jepang oleh mantan pemagang (kenshuusei). Metode kualitatif deskriptif digunakan dalam penelitian ini di bawah payung kajian pragmatik bahasa antara (interlanguage pragmatic) karena partisipan merupakan penutur asing bahasa Jepang. Pengumpulan data dilakukan menggunakan teknik melengkapi wacana secara lisan (oral-discourse completion test). Temuan pada penelitian ini di antaranya terdapat tiga tipe proses penolakan, yaitu 1) prapenolakan - penolakan utama - pasca penolakan; 2) pra-penolakan - penolakan utama; dan 3) penolakan utama - pasca penolakan. Pada tuturan penolakan ditemukan 2 bentuk penolakan yaitu penolakan langsung (direct refusal) dan penolakan tidak langsung (indirect refusal). Strategi yang digunakan dalam menolak yaitu strategi permintaan maaf, strategi alasan penolakan, strategi pernyataan alernatif, strategi pernyataan harapan, strategi
\end{abstract}


permintaan di masa depan, bentuk negasi, fukushi, dan aizuchi. Mayoritas strategi penolakan yang digunakan oleh mantan pemagang, yaitu strategi alasan penolakan dan hampir seluruh tuturan penolakan juga menggunakan ungkapan permintaan maaf.

Keywords: tindak tutur, tindak tutur penolakan, strategi penolakan, pragmatik interbahasa

\section{Pendahuluan}

Setiap harapan, permintaan, maupun permohonan yang diajukan dapat menimbulkan respon positif berupa penerimaan. Menurut Hermaji (2013:5) tindak tutur penerimaan merupakan ungkapan yang berisi tanggapan balik positif (berupa penerimaan) yang disampaikan penutur atau mitra tutur. Sehingga jika permintaan maupun permohonan tidak diterima oleh penutur atau mitra tutur, maka dapat dikatakan sebagai respon negatif berupa penolakan. Penolakan menunjukkan respon terhadap sesuatu yang dirasa tidak seiring dengan kemauan hati maupun kesanggupan dalam diri terhadap suatu permintaan, permohonan, dan atau ajakan. Beebe et al dalam Ghazanfari (2013:53-54) mengungkapkan bahwa penolakan dapat diungkapkan secara langsung dan tidak langsung. Penolakan tidak dapat diungkapkan dengan mudah karena tuturan penolakan berpotensi menyinggung perasaan maupun mempermalukan mitra tutur. Oleh karena itu, strategi dalam menolak sangat dibutuhkan agar penolakan dapat dimaklumi oleh mitra tutur dan hubungan antara penutur dan mitra tutur tetap terjalin dengan baik.

Tindak tutur penolakan orang Jepang sangat bervariasi dalam pengungkapannya dan berbeda dengan negara lain. Davies dan Ikeno dalam Martawijaya (2016:01) mengatakan bahwa jika masyarakat Jepang mempunyai perbedaan dengan mitra tutur, biasanya mereka mendengarkan pendapat mitra tuturnya dengan menyetujui, lalu menyampaikan ketidaksetujuan secara tidak langsung dan tidak jelas atau samar. Faktor kebiasaan atau budaya memiliki pengaruh terhadap strategi penolakan yang dilakukan oleh orang Jepang. Mereka lebih suka melakukan penolakan secara ambigu kepada mitra tutur, baik menggunakan ungkapan permintaan maaf, alasan, maupun ungkapan lainnya. Strategi penolakan yang digunakanpun dapat dipengaruhi oleh beberapa faktor seperti hubungan keakraban antara penutur dan mitra tutur, status sosial, umur, suasana hati penutur, tujuan tuturan, maupun situasi tuturan. Pada umumnya ungkapan penolakan yang digunakan oleh orang Jepang yaitu ちょっと”chotto”, す 
みません”sumimasen", dan ごめんなさい"gomennasai". Berikut adalah contoh peristiwa tuturan penolakan pada buku Minna no Nihongo 2:

小川幸子： ミラーさん、ちょっとお願いがあるんですが。

"Mira-san, chotto onegai ga arundesu ga."

'Saudara Miller, saya ingin meminta bantuan?'

ミラー 何ですか。

"Nan desu ka."

'Bantuan apa?'

小川幸子＼cjkstart実は８月にオーストラリアヘホームステイに行くんです。 "Jitsuwa hachi gatsu ni o-sutoraria e ho-mu sutei ni ikun desu."

'Sebenarnya saya akan pergi homestay ke Australia bulan Agustus.'

ミラー＜wide>ホホームステイですか。いいですね。

"Ho-mu sutei desuka. li desune."

'Home stay? Bagus ya.'

小川幸子元。

それで今友達と英語を勉強しているんですが、、、。

"Ee.

Sorede ima tomodachi to eigo o benkyou shite irun desu ga...."

'Ya'

'Lalu, sekarang saya sedang belajar bahasa Inggris dengan teman saya..'

ミラー ええ。

"Ee"

' $\mathrm{Ya}$ '

小川幸子なかなか上手にならないんです。

先生もいないし、英語で話すチャンスもないし、、。

ミラーさん、会話の先生になっていただけませんか。(ajakan)

"Naka naka jouzu ni naranain desu.

Sensei mo inai shi, eigo de hanasu chansu mo naishi...

Mira-san, kaiwa no sensei ni natte itadakemasenka?"

'Saya tidak begitu pandai.

Tidak ada guru dan tidak ada kesempatan untuk berbicara dengan bahasa Inggris juga...

Saudara Miller apakah anda bersedia menjadi guru percakapan bahasa Inggris saya?'

ミラー え?先生に?うーん、ちょつと仕事が、、。(penolakan) 
"E? Sensei ni? U-n, chotto shigoto ga...."

'Apa? Menjadi guru? Mm, ada pekerjaan mungkin....'

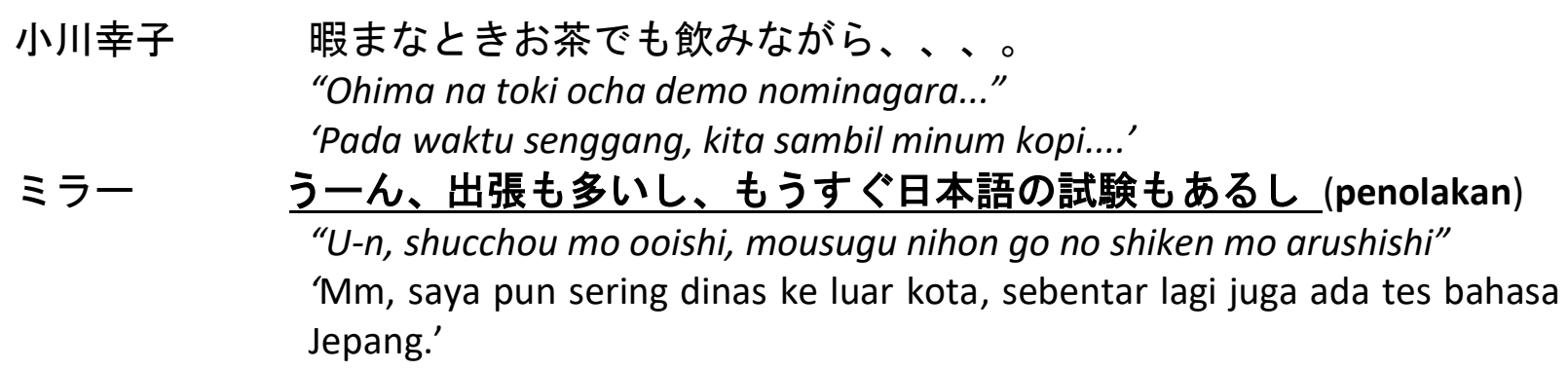

小川幸子 そうですか。

"Sou desu ka."

'Begitu ya.'
ミラー＜wide>すみません。(penolakan)
"Sumimasen."
'Maaf.'

Dalam percakapan di atas, terdapat peristiwa tutur antara Miller dan Ogawasachiko. Konteks percakapan tersebut menunjukkan bahwa Ogawasachiko memohon kepada Miller untuk menjadi guru percakapan bahasa Inggris, tetapi Miller menolaknya. Dalam peristiwa tutur tersebut Miller melakukan strategi penolakan dengan 3 tahap penolakan. Pertama menggunakan ungkapan "chotto" yang menunjukkan penolakan secara tidak langsung, kedua "shucchou moo oi shi, mou sugu Nihongo no shaken mo arushi" menunjukkan strategi alasan penolakan, dan terakhir menggunakan ungkapan"sumimasen" yang menunjukkan strategi permintaan maaf. Strategi yang digunakan Miller untuk menolak permohonan tersebut, dinilai sebagai satu usaha agar penolakan dapat dimaklumi, sehingga hubungan antara penutur dan mitra tutur tetap terjalin dengan baik.

Kana (2016:1) mengatakan bahwa orang Jepang cenderung melakukan penolakan secara ambigu maupun tidak jelas, karena mereka lebih memperhatikan perasaan dan menjaga hubungan dengan mitra tutur. Dengan demikian, tuturan penolakan secara tidak langsung dengan beberapa strategi yang digunakan secara bersamaan, merupakan sebuah usaha untuk meminimalkan keterancaman muka. 
Bersadarkan pada fakta tersebut, lalu bagaimana penutur asing bahasa Jepang, terutama para mantan pemagang (kenshuusei) orang Indonesia menolak permintaan atau permohonan dalam bahasa Jepang menjadi hal menarik yang perlu diteliti. Apabila orang Indonesia yang pernah tinggal di Jepang, apakah mereka dapat menggunakan tuturan penolakan beserta dengan strateginya seperti penutur asli orang Jepang?

Penulis tertarik untuk meneliti tuturan penolakan mantan pemagang karena mayoritas penelitian yang selama ini ada menggunakan sumber data dari film Jepang, dari pembelajar bahasa Jepang yang belum pernah ke Jepang, maupun pembelajar asing yang sedang belajar di Jepang. Adapun kriteria responden yang diambil adalah mantan pemagang (1-3 tahun), sudah pulang ke Indonesia dengan jarak 1-5 tahun, dan sedang bekerja di perusahaan Jepang atau tempat yang berhubungan dengan penggunaan bahasa Jepang di Indonesia selama kurang dari 5 tahun.

Hasil penelitian ini diharapkan dapat memberikan masukan bagi para penyelenggara pelatihan Bahasa Jepang bagi calon pemagang secara khusus dan bagi penyelenggara pembelajaran Bahasa Jepang, untuk tidak hanya mengajarkan bentuk tuturan tertentu, tetapi perlu diiringi dengan penggunaan suatu tuturan yang tidak terlepas dari konteks tuturan maupun latar belakang budaya masyarakat Jepang.

\section{Kajian Teoretis}

Pragmatik interbahasa atau interlanguage pragmatics menurut Kasper dan Blum-Kulka dalam Anita (2018:16) merupakan suatu cara yang digunakan penutur untuk memahami tindak linguistik dalam penggunaan bahasa kedua. Menurut Schauer interlanguage pragmatics dilatarbelakangi oleh dua disiplin ilmu yaitu Second Language Acquisition atau pemerolehan bahasa kedua dan ilmu pragmatik. Ilmu pragmatik digunakan pembelajar bahasa asing dalam melakukan penelitian untuk memahami arti dan penyampaian bahasa asing.

Menurut Kasper dan Rose dalam Anita (2018:17) pragmatik lintas bahasa terdiri dari 3 dasar, yaitu tindak tutur, implikatur percakapan, dan kesantunan.

1. Tindak tutur

Penggunaan bahasa tidak hanya sebagai alat berbicara dalam bentuk tuturan, tetapi juga berfungsi untuk menyampaikan maksud maupun tujuan yang diinginkan oleh penutur. 
2. Implikatur percakapan

Penutur dan mitra tutur harus bekerjasama saat berkomunikasi agar percakapan yang dilakukan menghasilkan suatu manfaat, sehingga penutur dan mitra tutur harus menggunakan prinsip kerja sama maksim relevansi.

3. Kesantunan

Tindak tutur yang diucapkan penutur asing atau non asli mengandung kesantuan dalam pragmatik lintas bahasa. Penutur non asli juga dapat mengekspresikan tuturan sesuai pandangannya dalam berkomunikasi lintas budaya.

Tindak tutur mempunyai beberapa fungsi seperti pernyataan, pertanyaan, perintah, maupun permintaan. Pada fungsi permintaan dapat menimbulkan reaksi positif maupun negatif. Reaksi positif yaitu dapat berupa persetujuan, sedangkan reaksi negatif yaitu berupa penolakan.

Dalam KBBI (2008:1477) penolakan diartikan sebagai proses, cara, perbuatan menolak. Kemudian menolak dalam bahasa Jepang disebut "kotowaru". Dalam kamus besar bahasa Jepang Kokugojiten (1982:329) kotowaru yaitu tidak melakukan atau tidak dapat menerima permintaan dari orang lain. Menurut Al-Kahtani dalam Widari (2016:12) penolakan merupakan respon negatif dari sebuah tawaran, permintaan, ajakan, dan sebagainya.

Berdasarkan definisi tersebut dapat disimpulkan bahwa tindak tutur menolak yaitu tindakan untuk menyampaikan perasaan tidak setuju atau ketidaksanggupan terhadap suatu ungkapan permintaan atau permohonan melalui tuturan.

Menolak suatu permintaan, ajakan, maupun undangan tidak hanya sekedar diucapkan tanpa adanya suatu pertimbangan. Dalam memberikan reaksi penolakan kepada mitra tutur, penutur hendaknya mempertimbangkan beberapa hal agar tidak menyakiti hati dan tidak mempermalukan mitra tutur, serta hubungan dapat tetap terjalin dengan baik. Oleh karena itu proses penolakan sangat diperlukan dalam suatu tuturan penolakan.

Ochi dan Suzuki (2013:138) menganalisis proses terjadinya tuturan penolakan dari Beebe et al yaitu: dalam contoh Beebe et al (1990:57) pada waktu diundang makam malam di rumah teman, penolakan pada umumnya (1) Maaf, (2) Malam ini saya akan nonton teater. (3) Mungkin lain kali saya akan datang. Pertama (permintaan maaf), (menjelaskan alasan tidak bisa hadir), lalu 
(memberikan penawaran lain). Kemudian penolakan terhadap permintaan untuk membantu pekerjaan (1) Um aku harap bisa membantumu, (2) tetapi saya punya banyak pekerjaan. (3) maaf, (keinginan membantu jika memungkinkan), (menyatakan alasan tidak bisa), (menyatakan penyesalan).

Contoh di atas menunjukkan tuturan penolakan yang terdiri dari 3 proses penolakan yaitu:

1. Pra-penolakan, dapat berwujud permintaan maaf maupun harapan.
a) I'm sorry: permintaan maaf
b) Well, I wish i could help you: menyatakan keinginan membantu jika keadaan memungkinkan

2. Penolakan (utama), dapat berwujud isi ditolaknya suatu permintaan berupa alasan.
a) I have theater tickets that night: menjelaskan alasan tidak bisa hadir
b) But I've lots of work to do: menyatakan alasan tidak bisa membantu pekerjaan

3. Pasca penolakan penolakan dapat berwujud penawaran di masa depan dan penyesalan.
a) Maybe I could come by later for a drink: menawarkan alternatif lain
b) I'm sorry: menyatakan penyesalan

Beebe et al dalam Ghazanfari (2013:53-54) mengklasifikasikan teori strategi penolakan ke dalam 2 kelompok yang sudah diverifikasi ke dalam bahasa Jepang oleh Kuroda Kaho, dan Miku Ishikawa (penutur asli orang Jepang ) yaitu sebagai berikut.

1. Penolakan langsung (direct refusal) (chokusetsuteki kotowari)

Penolakan langsung merupakan penolakan yang diucapkan secara jelas yang berhubungan dengan fakta bahwa penutur menyatakan ketidaksanggupannya dengan menggunakan proposisi negatif tanpa adanya makna ambiguitas. Tuturan dapat dikategorikan sebagai penolakan langsung apabila mengandung strategi berupa verba:

a. Verba Performatif, seperti: I decline atau"kotowari” 'saya menolak'.

b. Verba Non Performatif, seperti:

No atau "iie" 'tidak'

I can't atau "dekinai", "ikenai" "muri" 'saya tidak bisa' dan sejenisnya. 
2. Penolakan tidak langsung (indirect refusals) (kansestuteki kotowari)

Penolakan tidak langsung menunjukkan fakta bahwa penutur menyatakan ketidaksanggupannya terhadap penawaran, undangan, dan permintaan secara tidak langsung yang mengandung makna ambiguitas, samar, maupun tidak jelas. Penolakan tidak langsung menggunakan strategi dalam tuturannya agar tidak terjadi ketidaknyamanan antara penutur dan mitra tutur. Strategi penolakan tidak langsung mencakup beberapa jenis yaitu sebagai berikut.

a) Ungkapan permintaan maaf

Penutur memberikan jawaban berupa permintaan maaf yang berarti menolak, dan agar penolakan dapat diterima oleh mitra tutur. Contoh: "gomennasai", "sumimasen" 'Maaf'.

b) Alasan, penyebab, penjelasan

Penutur memberikan penolakan berupa alasan, penyebab, adan atau penjelasan terhadap suatu permintaan maupun ajakan agar penolakan dapat diterima oleh mitra tutur. Contoh: "watashi wa tesuto ga aru no" 'saya ada ujian'.

c) Janji penerimaan di masa depan

Permintaan atau ajakan ditolak oleh penutur, tetapi penutur menyatakan atau menawarkan pilihan bahwa permintaan atau ajakan dapat dilakukan di lain waktu atau selanjutnya. Contoh: "mata jikaisuru tsumoridesu" 'lain kali saya akan melakukanya'.

d) Pernyataan harapan

Penutur menolak suatu permintaan tetapi dengan memberikan pernyataan untuk membantu. Contoh: "watashi wa anata o tasuketai to omou" 'Saya harap dapat membantumu'. e) Pernyataan alternatif

Penutur menolak suatu permintaan tetapi mencoba memberikan penawaran lainnya kepada mitra tutur. Contoh: "watashi wa eiga o mirukoto ga suki" 'Saya lebih suka menononton film'.

f) Kondisi penerimaan waktu di masa depan dan di masa lalu. Penutur menolak dengan memberikan pernyataan yang berhubungan dengan masa lalu dan masa depan. Contoh: "moshi, watashi ga jyuubun na okane wo motte itara" 'Jika saya mempunyai cukup uang'.

g) Pernyataan prinsip 
Penutur menolak suatu permintaan atau ajakan dengan menyatakan prinsip kepada mitra tutur. Contoh: "watashi wa yuushoku no ato suguni sake o nondakoto wa nai" 'Saya tidak pernah minum sake setelah makan malam'.

h) Pernyataan filosofi

Penutur menolak suatu permintaan atau ajakan dengan menyatakan filosofi kepada mitra tutur. Contoh:" daremo risuku okashitakunai” 'siapapun tidak ingin mengambil resiko tersebut'.

i) Usaha untuk mencegah mitra tutur

1) Ancaman atau pernyataan negatif kepada pemohon. Contoh:

"Anata ga kono you ni watashi wo handan suru to shitte itara, watashi wa sore wo shinakatta."

'Jika saya tahu kamu akan menilai saya seperti ini, saya tidak akan pernah melakukannya.'

2) Menyampaikan rasa bersalah (seorang pelayan kepada pelanggan yang ingin duduk sebentar). Contoh:

"Watashi wa ocha wo chuumon suru dake no hito to seikei wo tateru koto wa dekinai." 'Saya tidak dapat mencari nafkah dari pelanggan yang hanya memesan teh.'

3) Mengkritik permintaan penutur atau pemohon. Contoh:

"Sore wa oroka na teian da." 'Itu saran yang konyol.'

j) Penerimaan berfungsi sebagai penolakan

1) Jawaban tidak pasti atau tidak spesifik

Contoh:

"Itsu anata ni agerareruka wakarimasen."

'Saya tidak tahu kapan saya bisa membantu anda.'

2) Jawaban kurang antusias

Contoh:

"Watashi wa daiyetto ni kyoumi wa arimasen"

'Saya tidak tertarik untuk diet.'

k) Penghindaran

1) Non verbal: diam, ragu-ragu, tidak melakukan apa-apa, dan pergi 
2) Verbal:

(1). Mengalihkan topik pembicaraan

(2). Membuat lelucon

(3). Pengulangan permintaan sebelumnya

(4). Membatasi

Contoh verbal: "Kangaete okimasu" 'Saya akan mempertimbangkannya'.

\section{Metode Penelitian}

Jenis penelitian ini termasuk dalam kajian pragmatik bahasa antara (interlanguage pragmatic) karena data tuturan dihasilkan oleh pentur asing. Metode yang dilakukan dalam penelitian ini yaitu metode kualitaif yang bersifat deskriptif. Djajasudarma dalam Adistya (2016:2) menyatakan bahwa metode kualitatif merupakan prosedur yang menghasilkan data deksriptif berupa data tertulis ataupun lisan. Bahan analisis berupa data lisan yang sudah ditranskripkan dari mantan pemagang orang Indonesia.

Kriteria responden yaitu mantan pemagang di Jepang berkewarganegaraan Indonesia yang sudah pulang ke Indonesia, dan tinggal di Indonesia dengan rentang waktu 1-5 tahun sejak kepulangannya dari Jepang. Jumlah responden yang dapat dijangkau peneliti dalam penelitian ini sebanyak 19 orang, yaitu 12 laki-laki dan 7 perempuan.

Metode tes melengkapai wacana secara lisan (oral discourse completion test) digunakan untuk pengumpulan data. Metode ini sering digunakan untuk pengumpulan data dengan responden yang bukan penutur asli dalam kajian interlanguage pragmatic (Aryanto, 2020: 96).

Teknik Discource Completion Task (DCT) merupakan teknik pemerolehan data berupa kuesioner yang sudah lazim digunakan oleh para peneliti pragmatik seperti Zhang dan Wang (1997) tentang tuturan permintaan orang Cina dan Wang (2001) tentang tuturan penolakan orang Cina dan Amerika. DCT berisi deskripsi situasi tertentu dalam bentuk tertulis seperti yang digunakan oleh Blum Kulka et al (1989). Dalam teknik ini, data diperoleh dengan cara membagikan pertanyaan kemudian partisipan akan menjawab tuturan berdasarkan situasi atau konteks yang sudah dibuat. Menurut Kasper dan Dahl dalam Maiko Kobayakawa (2006:1-2) terdapat 2 jenis DCT yaitu

1. Open Questionnaires (pertanyaan) 
Kuesioner berupa deskripsi situasi tertentu tanpa menampilkan sebuah dialog atau percakapan. Contoh: Teman Anda telah melakukan kecurangan dalam suatu lomba dan akhirnya memenangkan lomba tersebut. Anda tidak suka dengan kecurangan yang dilakukan teman anda. Apa yang akan anda lakukan?

\section{Discourse Completion (Penyelesaian Wacana)}

Kuesioner berupa deskripsi situasi tertentu dengan menampilkan sebuah dialog atau percakapan. Contoh: Anda ingin belajar di kelas, tetapi terdengar suara musik dari kelas lantai bawah. Anda tidak mengenal siswa dari kelas lantai bawah, tetapi anda meminta tolong kepadanya untuk mengecilkan suara musik tersebut.

Anda :

\section{Siswa :}

Kelebihan dari teknik DCT yaitu peneliti dapat mendapatkan data sesuai konteks atau situasi yang diinginkan (pengendalian konteks), data dapat terkumpul dalam jumlah banyak dengan waktu yang singkat, dan dapat memperoleh hasil tambahan yang tidak terduga.

Variasi DCT dapat dilihat bagaimana informan diberikan impuls agar menghasilkan data yang diinginkan. Ada beberapa cara yaitu secara tertulis (written-DCT) dan secara lisan (oralDCT). Pada penelitian ini, peneliti menggunakan written-DCT dengan pertimbangan cara ini lebih fleksibel dengan kesanggupan informan dari sisi waktu pengerjaannya. Terdapat dua Konteks percakapan yang telah disiapkan peneliti sebagai pemancing data. Kemudian responden diminta untuk merespon secara lisan terhadap konteks tuturan yang diberikan. Berikut isi konteks yang diberikan ke responden. Konteks pertama (hubungan asimetris atasan-bawahan)

Anda diminta oleh atasan untuk menggantikan seseorang untuk rapat di kantor, tetapi Anda tidak bisa. Bagaimana cara Anda menolak permintaan dari atasan?

Atasan san wa kaze o hiita node, kawarini kaigi o shite moraemasuka? responden :

Konteks kedua (hubungan simetris-dekat) 
Teman kantor (hubungan jarak sosial dekat dan akrab) meminta tolong kepada Anda untuk membantu menyiapkan dokumen rapat, tetapi Anda tidak bisa membantunya. Bagaimana cara Anda menolak permintaan dari teman kantor?

Teman kantor : Sumimasen, kaigi no shiryou ga amari wakaranakute, yokattara kaigi no shiryou o tetsudatte moraeru?

Responden :

\section{Hasil dan Pembahasan}

\subsection{Atasan-bawahan (hubungan vertikal)}

Tabel 1 berikut menunjukkan presentase tuturan penolakan berdasarkan masing-masing variabel dinamis. Berdasarkan proses penolakan ditemukan data 63,16 \% pra-penolakan penolakan utama - pasca penolakan, 31,58\% pra-penolakan - penolakan utama, dan 5,26\% penolakan utama - pasca penolakan. Berdasarkan bentuk penolakan ditemukan data $42,11 \%$ penolakan langsung (direct refusal) dan 57,89\% penolakan tidak langsung (indirect refusal). Berdasarkan strategi penolakan dari setiap 19 data ditemukan 42,11\% bentuk negasi, 100\% ungkapan permintaan maaf, 100\% alasan, 10,52\% permintaan di masa depan, 15,79\% pernyataan alternatif, 36,84\% fukushi, dan 63,16\% aizuchi.

Tabel 1 Presentase Strategi Tuturan Penolakan Berdasarkan Hubungan Vertikal

\begin{tabular}{llr}
\hline \multirow{2}{*}{ Proses penolakan } & \multicolumn{1}{c}{ VERTIKAL } & $\%$ \\
\cline { 2 - 3 } & Pra-utama-pasca & 63,16 \\
\cline { 2 - 3 } & Pra-utama & 31,58 \\
\cline { 2 - 3 } Bentuk penolakan & Direct refusal & 5,26 \\
\hline & Indirect refusal & 42,11 \\
\hline Strategi penolakan & Bentuk negasi & 57,89 \\
\cline { 2 - 3 } & Permintaan maaf & 42,11 \\
\hline & Alasan & 100 \\
\hline & Permintaan dimasa depan & 100 \\
\cline { 2 - 3 } & Pernyataan alternatif & 10,52 \\
\hline & Fukushi & 15,79 \\
\hline & Aizuchi & 36,84 \\
\hline
\end{tabular}

\subsubsection{Data 1}

(1) ええと、すみませんが、アリさんの代わりにはできないと思いますがこれからカスタマー と約束のミーティングがありますで、申し訳ありませんが。 
"Eeto, sumimasen ga, Ari san no kawarini wa dekinai to omoimasu ga korekara kasutamaa to yakushoku no miitingu ga arimasude, moushiwake arimasen ga."

'Bagaimana ya, maaf, saya tidak dapat menggantikan Pak Ari untuk rapat karena sekarang saya ada janji rapat dengan kostumer, saya mohon maaf.'

Data tuturan (1) ditemukan 3 proses yang digunakan dalam menolak yaitu strategi prapenolakan (eeto, sumimasen ga), penolakan utama (Ari san no kawarini wa dekinai to omoimasu ga), dan strategi pasca-penolakan (korekara kasutamaa to yakushoku no miitingu ga arimasude, moushiwake arimasen ga.)

Strategi pra-penolakan aizuchi "eeto" berfungsi sebagai penanda negatif sebelum memasuki penolakan utama yang menunjukkan kekhawatiran terhadap suatu penolakan. Ungkapan permintaan maaf "sumimasen $g a$ " merupakan salah satu strategi untuk menolak. Berdasarkan kamus besar bahasa Jepang kokugojiten (1982:468) kata sumimasen mempunyai arti rasa terimakasih, permintan maaf, dan rasa penyesalan terhadap sesuatu yang tidak bisa dilakukan. Permintaan maaf yang diikuti partikel " $g a$ " menunjukkan bentuk sopan permintaan maaf. Maka jika dilihat dari konteks tuturan, maksud dari uangkapan sumimasen ga yaitu untuk mengekspresikan suasana hati 'maaf' yang halus dan sopan kepada mitra tutur sebelum memasuki penolakan utama.

Strategi penolakan utama terdapat pada tuturan "Ari san no kawarini wa dekinai to omoimasu ga" dengan ditandai oleh "dekinai" yang merupakan bentuk negasi futsu-kei (bentuk biasa) dari dekimasen. Karena di dalam tuturan tersebut menggunakan bentuk negasi (dekinai), maka tuturan tersebut dapat disimpulkan sebagai tuturan penolakan langsung (direct refusal). Pada kalimat penolakan utama juga diakhiri dengan " $g a$ " yang berfungsi untuk memperhalus dalam menolak.

Strategi pasca penolakan menggunakan strategi alasan penolakan dan permintaan maaf. Strategi alasan "korekara kasutamaa to yakushoku no miitingu ga arimasu node" menjelaskan alasan yang lebih spesifik yaitu karena ada janji bertemu dengan tamu/kostumer. Penggunaan strategi alasan penolakan digunakan untuk menjelaskan alasan ditolaknya suatu permintaan. Ungkapan permintaan maaf "moushiwake arimasen ga" merupakan salah satu strategi untuk menolak. Moushiwake arimasen merupakan bentuk sopan dari sumimasen yang artinya mohon maaf. Permintaan maaf yang diikuti partikel “ $g a$ ” menunjukkan bentuk sopan permintaan maaf. 
Maka jika dilihat dari konteks tuturan, maksud dari ungkapan moushiwake arimasen ga yaitu untuk mengekspresikan suasana hati 'maaf' dan rasa penyesalan yang sangat dalam dan sopan karena sudah menolak permintaan mitra tutur.

\subsubsection{Data 2}

(2) あ一すみません。今ちょっと急用な資料がありますて、申し訳ありません。

"A-, sumimasen. Ima chotto kyuuyou na shiryou ga arimasute, moushiwake arimasen."

'Ah maaf. Karena sekarang ada dokumen yang harus segera saya selesaikan, saya mohon maaf.'

Data tuturan (6) ditemukan 3 proses yang digunakan dalam menolak yaitu strategi prapenolakan (a-sumimasen. Ima chotto) penolakan utama (kyuuyou na shiryou ga arimasute), dan strategi pasca-penolakan (moushiwake arimasen).

Strategi pra-penolakan menggunakan aizuchi, strategi permintaan maaf dan, fukushi chotto. Auzuchi " $a$-" berfungsi sebagai penanda negatif sebelum memasuki penolakan utama yang menunjukkan kekhawatiran terhadap suatu penolakan. Ungkapan permintaan maaf "sumimasen ga" merupakan salah satu strategi untuk menolak. Berdasarkan kamus besar bahasa Jepang kokugojiten (1982:468) kata sumimasen mempunyai arti rasa terimakasih, permintan maaf, dan rasa penyesalan terhadap sesuatu yang tidak bisa dilakukan. Maka maksud dari uangkapan sumimasen ga pada tuturan pra-penolakan yaitu untuk mengekspresikan suasana hati 'maaf' kepada mitra tutur sebelum memasuki penolakan utama. Permintaan maaf yang diikuti dengan " $g a$ " juga dapat menunjukkan rasa penyesalan yang halus dan sopan dalam suatu penolakan. Fukushi "chotto" digunakan untuk melunakkan tuturan sebelum memasuki sebuah penolakan agar penolakan dapat berterima.

Strategi penolakan utama menggunakan strategi alasan penolakan. Strategi alasan "kyuuyou na shiryou ga arimasute" menjelaskan alasan yang lebih spesifik yaitu karena ada dokumen yang harus segera diselesaikan. Penggunaan strategi alasan penolakan tersebut digunakan untuk mengungkapkan bahwa permintaan tersebut belum terpenuhi. Data tuturan penolakan yang diucapkan merupakan jenis tuturan penolakan tidak langsung. Karena di dalam tuturan tersebut tidak menggunakan bentuk negasi iie (tidak), dekimasen (tidak bisa), dan sejenisnya, maka tuturan tersebut dapat disimpulkan sebagai tuturan penolakan tidak langsung (indirect refusal). 
Strategi pasca penolakan menggunakan ungkapan permintaan maaf "moushiwake arimasen" merupakan salah satu strategi untuk menolak. Moushiwake arimasen merupakan bentuk sopan dari sumimasen yang artinya mohon maaf. Apabila terdapat ungkapan moushiwake arimasen, maka maksud dari uangkapan tersebut yaitu untuk mengekspresikan suasana hati 'maaf' dan rasa penyesalan yang sangat dalam karena sudah menolak permintaan mitra tutur.

\subsubsection{Data 3}

(3)すみません、私の仕事がまだいっぱいありますのでちょっと、。

"Sumimasen, watashi no shigoto ga mada ippai arimasu node chotto.."

'Maaf, karena pekerjaan saya juga masih banyak...'

Data tuturan (11) ditemukan 2 proses yang digunakan dalam menolak yaitu strategi prapenolakan (Sumimasen, watashi no shigoto ga mada ippai arimasu node) dan penolakan utama (chotto).

Strategi pra-penolakan menggunakan ungkapan permintaan maaf dan strategi alasan. Ungkapan permintaan maaf "sumimasen" merupakan salah satu strategi untuk menolak. Berdasarkan kamus besar bahasa Jepang kokugojiten (1982:468) sumimasen mempunyai arti rasa terimakasih, permintan maaf, dan rasa penyesalan terhadap sesuatu yang tidak bisa dilakukan. Maka maksud dari uangkapan sumimasen yaitu untuk mengekspresikan suasana hati 'maaf' kepada mitra tutur sebelum memasuki penolakan utama. Strategi alasan "watashi no shigoto ga mada ippai arimasu node" menjelaskan alasan yang lebih spesifik yaitu karena banyak pekerjaan. Penggunaan strategi alasan penolakan tersebut digunakan untuk mengungkapkan bahwa permintaan tersebut belum terpenuhi.

Strategi penolakan utama menggunakan fukushi berupa ungkapan "chotto". Fukushi "chotto" dalam tuturan mengandung unsur keberatan atau ketidaksanggupan terhadap suatu permintaan yang mengarah pada penolakan. Data tuturan penolakan yang diucapkan merupakan jenis tuturan penolakan tidak langsung. Karena di dalam tuturan tersebut tidak menggunakan bentuk negasi iie (tidak), dekimasen (tidak bisa), dan sejenisnya, maka tuturan tersebut dapat disimpulkan sebagai tuturan penolakan tidak langsung (indirect refusal). 


\subsection{Sesama teman kantor (hubungan horizontal)}

Tabel 2 Presentase Strategi Tuturan Penolakan Berdasarkan Hubungan Horizontal

\begin{tabular}{llr}
\hline & & HORIZONTAL \\
\hline Proses penolakan & Pra-utama-pasca & 84,21 \\
\cline { 2 - 3 } & Pra-utama & 10,53 \\
\cline { 2 - 3 } Bentuk penolakan & Utama-pasca & 5,26 \\
\hline Strategi penolakan & Direct refusal & 26,32 \\
\cline { 2 - 3 } & Indirect refusal & 73,68 \\
\hline & Bentuk negasi & 26,32 \\
\cline { 2 - 3 } & Permintaan maaf & 89,47 \\
\hline & Alasan & 100 \\
\hline Permintaan di masa depan & 21,05 \\
\hline Pernyataan alternatif & 10,53 \\
\hline & Harapan & 10,53 \\
\hline & Fukushi & 36,84 \\
\hline & Aizuchi & 84,21 \\
\hline
\end{tabular}

Tabel 2 menunjukkan presentase tuturan penolakan (hubungan horizontal) berdasarkan masing-masing variabel dinamis. Berdasarkan proses penolakan ditemukan data $84,21 \%$ prapenolakan - penolakan utama - pasca penolakan, 10,53\% pra-penolakan - penolakan utama, dan 5,26\% penolakan utama - pasca penolakan. Berdasarkan bentuk penolakan ditemukan data 26,32\% penolakan langsung (direct refusal) dan 73,68\% penolakan tidak langsung (indirect refusal). Berdasarkan strategi penolakan dari setiap 19 data ditemukan 26,32\% bentuk negasi, $89,47 \%$ ungkapan permintaan maaf, $100 \%$ alasan, 21,05\% permintaan di masa depan, 10,53\% pernyataan alternatif, 10,53\% harapan, 36,84\% fukushi, dan $84,21 \%$ aizuchi.

\subsubsection{Data 4}

(4) えー、今はごめんね。忙しくてムリだと思う。もし後でどう?

"E-, ima wa gomenne. Isogashikute muri da to omou. Moshi atode dou?"

'Um, maaf ya. Karena hari ini saya sibuk, sepertinya tidak bisa. Kalau nanti bagaimana?'

Data tuturan (13) ditemukan 3 proses yang digunakan dalam menolak yaitu strategi prapenolakan (E-, ima wa gomenne. Isogashikute) penolakan utama (muri da to omou), dan strategi pasca-penolakan (moshi atode dou?).

Strategi pra-penolakan menggunakan aizuchi, ungkapan permintaan maaf dan strategi alasan. Aizuchi "e-" berfungsi sebagai penanda negatif sebelum memasuki penolakan utama yang menunjukkan kekhawatiran terhadap suatu penolakan. Ungkapan permintaan maaf 
"gomen" merupakan salah satu strategi untuk menolak. Berdasarkan kamus besar bahasa Jepang kokugojiten (1982:333) gomen merupakan kata yang menunjukkan perasaan menolak. Apabila terdapat ungkapan gomen, maka maksud dari uangkapan tersebut yaitu untuk mengekspresikan suasana hati 'maaf' kepada penutur sebelum memasuki suatu penolakan. Strategi alasan "isogashikute" menjelaskan alasan yang lebih spesifik yaitu karena sibuk. Penggunaan strategi alasan penolakan tersebut digunakan untuk mengungkapkan bahwa permintaan tersebut belum terpenuhi.

Strategi penolakan utama terdapat pada tuturan (muri da to omou) dengan ditandai oleh "muri". Berdasarkan kamus besar bahasa Jepang Kokugojiten (1982:890) "muri" mempunyai arti hal yang tidak ingin dilakukan, hal yang tidak bisa dilakukan, dan menghadapi hal yang berlawanan. Karena di dalam tuturan tersebut menggunakan kata muri yang mempunyai makna sama dengan bentuk negasi (dekimasen), maka tuturan tersebut dapat disimpulkan sebagai tuturan penolakan langsung (direct refusal). Strategi pasca penolakan menggunakan permintaan di masa depan "moshi atode dou" yang menunjukkan bahwa suatu permintaan ditolak oleh penutur dan menawarkan bantuan dilain waktu atau selanjutnya.

\subsubsection{Data 5}

(5) 申し訳ありませんが私は助けてと思っていますが私は間違っているのではないかと心配して います。

"Moushiwake arimasen ga watashi wa tasukete to omotte imasu ga watashi wa machigatte iru no dewanai ka to shinpai shite imasu."

'Saya mohon maaf, Saya ingin membantu, tetapi saya khawatir kalau ada yang salah.'

Data tuturan (20) ditemukan 2 proses yang digunakan dalam menolak yaitu strategi prapenolakan (moushiwake arimasen ga watashi wa tasukete to omotte imasu ga) dan penolakan utama (watashi wa machigatte iru no dewanai ka to shinpai shite imasu).

Strategi pra-penolakan menggunakan ungkapan permintaan maaf dan strategi harapan. Ungkapan permintaan maaf "moushiwake arimasen" merupakan salah satu strategi untuk menolak dan bentuk sopan dari sumimasen yang artinya mohon maaf. Permintaan maaf yang diikuti partikel "ga" menunjukkan bentuk sopan permintaan maaf. Maka jika dilihat dari konteks tuturan, maksud dari ungkapan moushiwake arimasen ga yaitu untuk mengekspresikan suasana 
hati 'maaf' dan rasa penyesalan yang sangat dalam dan sopan kepada mitra tutur sebelum memasuki penolakan utama.

Strategi penolakan utama menggunakan strategi alasan penolakan. Strategi alasan "watashi wa machigatte iru no dewanai ka to shinpai shite imasu" menjelaskan alasan yang lebih spesifik yaitu karena khawatir jika terdapat kesalahan. Penggunaan strategi alasan penolakan digunakan untuk mengungkapkan bahwa permintaan tersebut belum terpenuhi. Data tuturan penolakan yang diucapkan merupakan jenis tuturan penolakan tidak langsung. Karena di dalam tuturan tersebut tidak menggunakan bentuk negasi iie (tidak), dekimasen (tidak bisa), dan sejenisnya, maka tuturan tersebut dapat disimpulkan sebagai tuturan penolakan tidak langsung (indirect refusal).

\subsubsection{Data 6}

(6) 自分の仕事は三十分までに終わらなきや、ごめんね。

“Jibun no shigoto wa sanjuppun madeni owaranakya, gomen ne."

'Saya harus menyelesaikan pekerjaan saya 30 menit lagi, maaf ya.

Data tuturan (21) ditemukan 2 proses yang digunakan dalam menolak yaitu strategi penolakan utama (jibun no shigoto wa sanjuppun madeni owaranakya) dan strategi pascapenolakan (gomen ne).

Strategi penolakan utama menggunakan strategi alasan penolakan. Strategi alasan "jibun no shigoto wa sanjuppun madeni owaranakya" menjelaskan alasan yang lebih spesifik yaitu karena harus menyelesaikan pekerjaan dalam 30 menit. Penggunaan strategi alasan penolakan digunakan untuk mengungkapkan bahwa permintaan tersebut belum terpenuhi. Data tuturan penolakan yang diucapkan merupakan jenis tuturan penolakan tidak langsung. Karena di dalam tuturan tersebut tidak menggunakan bentuk negasi iie (tidak), dekimasen (tidak bisa), dan sejenisnya, maka tuturan tersebut dapat disimpulkan sebagai tuturan penolakan tidak langsung (indirect refusal).

Strategi pasca penolakan menggunakan strategi ungkapan permintaan maaf. Ungkapan permintaan maaf "gomen ne" merupakan salah satu strategi untuk menolak. Berdasarkan kamus besar bahasa Jepang kokugojiten (1982:333) gomen merupakan kata yang menunjukkan perasaa menolak. Maka maksud dari uangkapan gomen ne untuk mengekspresikan rasa penyesalan karena sudah menolak permintaan mitra tutur. 


\section{Simpulan}

Berdasarkan hasil penelitian lapangan mengenai strategi tuturan penolakan mantan kenshuusei (pemagang), ditemukan 38 data tuturan penolakan mengandung 3 tipe proses penolakan yaitu pra-penolakan - penolakan utama - pasca penolakan, pra-penolakan penolakan utama, dan penolakan utama - pasca penolakan. Pada tuturan penolakan ditemukan 8 strategi yang digunakan dalam menolak yaitu strategi permintaan maaf, strategi alasan penolakan, strategi pernyataan alernatif, strategi pernyataan harapan, strategi permintaan di masa depan, bentuk negasi, fukushi chotto, dan aizuchi.

Pada proses penolakan antara atasan-bawahan (hubungan vertikal) ditemukan 12 data proses penolakan (pra-penolakan - penolakan utama - pasca penolakan), 6 data (pra-penolakan - penolakan utama), dan 1 data (penolakan utama - pasca penolakan). Pada bentuk penolakan ditemukan 8 data penolakan langsung (direct refusal) dan 11 data penolakan tidak langsung (indirect refusal). Strategi yang digunakan yaitu strategi permintaan maaf, alasan, pernyataan alternatif, permintaan di masa depan, bentuk negasi, fukushi chotto, dan aizuchi.

Pada proses penolakan antara sesama teman kantor (hubungan horizontal) ditemukan 16 data proses penolakan (pra-penolakan - penolakan utama - pasca penolakan), 2 data (prapenolakan - penolakan utama), dan 1 data (penolakan utama - pasca penolakan Pada bentuk penolakan ditemukan 5 data penolakan langsung (direct refusal) dan 14 data penolakan tidak langsung (indirect refusal). Strategi yang digunakan yaitu strategi permintaan maaf, alasan, pernyataan alternatif, pernyataan harapan, permintaan di masa depan, bentuk negasi, fukushi chotto, dan aizuchi.

Dari hasil penelitian dapat disimpulkan bahwa mayoritas tuturan penolakan mantan kenshuusei yaitu menggunakan tipe proses penolakan (pra-penolakan - penolakan utama - pasca penolakan). Bentuk penolakan yang sering digunakan yaitu berupa penolakan tidak langsung dikarenakan para mantan kenshuusei pernah magang ke Jepang dan berkomunikasi secara langsung dengan orang Jepang. Mayoritas tuturan penolakan yang digunakan mantan kenshuusei yaitu strategi alasan penolakan dan hampir seluruh tuturan mengandung ungkapan permintaan maaf dan aizuchi. 


\section{Referensi}

Adistya, R. (2016). Ungkapan Penolakan Ditinjau dari Prinsip Kerjasama dalam Anime Itazura na Kiss Karya Tada Kaoru. Goken, 3, 125-130.

Anita, T. D. (2017). Wujud Tindak Tutur Pujian Mahasiswa Sastra Jepang Universitas Dian Nuswantoro. Semarang: Skripsi Universitas Dian Nuswantoro.

Arifiany, N., Ratna, M. P., \& Trahutami, S. I. (2016). Pemaknaan Tindak Tutur Direktif dalam Komik "Yowamushi Pedal Chapter 87-93". Jurnal Japanese Literature, 2, 1-11.

Aryanto, Bayu. (2020). Validitas dan Reliabilitas Tes Elengkapi Wacana pada Penelitian Pragmatik Bahasa Antara (Interlanguage Pragmatics). LITE: Jurnal Bahasa, Sastra, dan Budaya, 16 (1), 95-105.

Departemen Pendidikan Nasional. (2008). Kamus Besar Bahasa Indonesia Pusat Bahasa Edisi Keempat. Jakarta: PT Gramedia Pustaka Utama.

Dewi, R. N., Kartika, D., \& Syahrial . (2013). Tindak Tutur Menolak dalam Bahasa Jepang Pada Film Asuko March. E-Jurnal Universitas Bung Hatta, 2, 1-14.

Ghazanfari, M. (2013). Investigating cross-linguistic differences in refusal speech act among native Persian and English speakers. International Journal of Research Studies in Language Learning, 49-63.

Haruhiko, K. (1982). Gakken Shougaku Kokugojiten. Tokyo: Gakken Inc.

Hermaji, B. (2013). Tindak Tutur Penerimaan dan Penolakan dalam Bahasa Indonesia. Jurnal Cakrawala ISSN 1858-449, 7, 1-10.

Jauhari, E. (2018). Alat-alat Kesantunan Kritik dalam Masyarakat Jawa Surabaya: Kajian Pragmatik. Mozaik Humaniora, 18, 167-177.

Jumanto. (2017). Pragmatik; Dunia Linguistik Tak Selebar Daun Kelor Edisi 2. Yogyakarta: Morfalingua.

Kana, Y., Aibonotika, A., \& Rahayu, N. (2016). Analisis Tindak Tutur Penolakan Bahasa Jepang. Pendidikan Bahasa Jepang FKIP Universitas Negeri Riau, 1-7.

Kanokwan, L. (1997). Nihongo Gakusha ni Mirareru [Kotowari] no Hyougen: Nihongo Bogowasha to Kurabete. Sekai no Hihongo Kyouiku, 7, 97-112.

Kimiko, O., \& Suzuki, M. (2013). Komyunike-shon Nouryoku no Koujou no Tame ni -Eiga ni Manabu [Kotowari] no Sutorateji-. ATEM Journal, 18, 137-150.

Lien, V. T. (2013). Jakunensou ni Okeru Kandoushi no Dutai Kenkyuu. Yamaguchi: Hakushironbun Yamaguchi Daigaku.

Maiko, K. (2006). Chuukan Gengou Goyouron Kenkyuu ni Okeru DCT. Gengo Kyouiku Kenkyuuhou, 1-4.

Martawijaya, A. P. (2016). Analisis Penggunaan Strategi Penolakan Tidak Langsung dalam Bahasa Jepang Oleh Mahasiswa Bahasa Jepang STBA Yapari ABA Bandung. Jurnal Sora, 1-15.

Okamoto, S., \& Saito, S. (2004). Nihongo Fukushi Chotto ni OkeruTagisei to Kinou. Hokkaidou Bunkyou Daigaku Ronshuu, 5, 65-75.

Pusat Bahasa Departemen Pendidikan Nasional. (2002). Kamus Besar Bahasa Indonesia Edisi Ketiga. Jakarta: Balai Pustaka.

Reskhi, T. I., \& Pratita, I. I. (2016). Penggunaan Tindak Tutur Ekspresif dalam Serial Drama Rich Man Poor Woman 「リッチマン。プアウーマ」 Karya Naoka Adachi. E-Journal Linguistik Bahasa Jepang, 145-155. 
Saifudin, A. (2019). Teori Tindak Tutur dalam Studi Linguistik Pragmatik. LITE: Jurnal Bahasa, Sastra, dan Budaya, 15 (1), 1-16.

Saifudin, A. (2018). Konteks dalam Studi Linguistik Pragmatik. LITE: Jurnal Bahasa, Sastra, dan Budaya, 14 (2), 108-117.

Shimizu, Y., Ishida, M., \& Kishie, S. (2011). Irai ni Taisuru Kotowari Hyougen ni Tsuite. Yama Gengo Bunka Kenkyuu, 19, 147-161.

Tanaka, Y., Sawada, S., Shigekawa, A., Makino, A., \& Mikogami, K. (1998). Minna no Nihongo Shokyuu Ni Dai Ni Han Honsatsu. Tokyo: 3A Corporation.

Widari, F. R. (2016). Strategi Tuturan Penolakan Mahasiswa Sastra Jepang Universitas Dian Nuswantoro. Semarang: Skripsi Universitas Dian Nuswantoro. 